\title{
As Políticas de Promoção da Saúde e a Questão dos Lugares APRENDENTES
}

\author{
POLITICS FOR HEALTH PROMOTION AND THE “LEARNING PLACES”
}

Jean-Jacques Schaller ${ }^{(*)}$

\section{RESUMO}

Qual o poder de uma política de promoção da saúde se esta não se arrisca nos caminhos da participação democrática, envolvendo de maneira recíproca os profissionais de saúde e os habitantes locais? Estamos hoje, historicamente, diante de duas representações que provocam rupturas graves. A primeira separa especialistas e leigos; a segunda, aprofunda a distância entre os políticos (os eleitos) e os cidadãos comuns. Devemos então propor um "fazer juntos" para criar o debate, a confrontação, e assim construir um mundo comum. A partir da perspectiva do sujeito ativo que se transformando, modifica o mundo de incertezas que é o seu próprio, este artigo pretende abordar a questão do "lugar" onde se desenrola o agir social. Como um lugar pode ser um "lugar aprendente"? Como o lugar participa da ação coletiva, enquanto expressão de identidade cultural e de solidariedade? Uma política de promoção da saúde pode, então, favorecer a ação transformadora que propõe a exploração do mundo a partir da aprendizagem, da experimentação, da deliberação e do respeito à pluralidade?

\section{Palavras-chave}

Democracia; Políticas Públicas; Promoção da Saúde.

${ }^{*}$ ) Universidade Paris 13/Nord, Centro de Pesquisas Interuniversitárias Experice (Experiência, Recursos Culturais, Educação) Paris 13/Nord - Paris 8/Saint-Denis. E-mail : schaller@univ-paris13.fr. Recebido em 31.7.07. Aprovado em 07.04.08 


\begin{abstract}
What is the power of a health promotion politcs if it does not take the risk of walking in a democratic participation way, involving health care professionals and local people in a reciprocity manner? Today we are historically facing two representations that cause serious disruptions. The first one separates experts and laymen; the second, deepens the gap between politicians (the elected) and the citizen. We should then propose a "making together" in order to create the debate, the confrontation, to build a common world. From the perspective of the individual who transforming himself, changes his own world of uncertainties, this article aims to address the question of the "place" where the social action happens. How a place can be a "place of learning"? How the place participates of a collective action, as an expression of cultural identity and solidarity? A policy of health promotion can favorize the transforming action which proposes a exploration of the world based on learning, experimentation, deliberation and respect for plurality?
\end{abstract}

\title{
Keywords
}

Democracy; Health Promotion; Public Politics.

\section{UMA FRASEOLOGIA REPLETA DE BOAS INTENÇÕES!}

Os objetivos gerais das políticas de promoção de saúde afirmam, freqüentemente, terem como meta a melhora do bem-estar físico, mental, social e ambiental dos habitantes de territórios, sejam eles Estados, regiões, cidades ou vilas. Esta noção de "saúde" depende, em larga medida, das condições da vida cotidiana(1), englobando educação, trabalho, lazer, cultura, meio ambiente físico e socioeconômico, mobilidade, acessibilidade aos serviços; em resumo, uma "forma" de vida que tem um papel determinante sobre a saúde dos "habitantes locais" no sentido de "estar no mundo" como proposto por M. Heidegger ${ }^{(2)}$.

Estas orientações políticas produzem um discurso decisório clássico daqueles que administram estes territórios, de como eles devem agir de maneira coordenada e em parceria, diante da multiplicidade de fatores que se conjugam, para a melhoria da saúde da população. Podemos notar, como o discurso político e institucional, freqüentemente, exorta sua proximidade

(1) LEFEBVRE, H. Critique de la vie quotidienne: fondements d'une sociologie de la quotidienneté. Paris: L'Arche, 1980. t. 2. [1961].

(2) HEIDEGGER, M. L'être et le temps. Paris: Gallimard, 1972. [1927]. 
com as demandas da população, querendo mostrar que os tomadores de decisão podem, naturalmente, apoiar-se nesta população.

Pretendemos aqui apontar uma concepção de política de promoção da saúde - cerne de uma política de saúde - que se compreende integrada a todos os aspectos e espaços da vida em sociedade. Assim, um território saudável é um lugar que, ao mesmo tempo, consegue oferecer melhor qualidade de vida a seus habitantes, com redução das desigualdades, promove acesso igualitário aos serviços coletivos e promete saúde para todos. Trata-se de pensar o território em termos de espaço solidário, imaginando qualidade de vida em sociedade, considerando-se as determinantes sociais, econômicas e ambientais que permitem implementar uma política coerente, atenta à qualidade de vida de todos os habitantes. A ação sobre os indivíduos implica em considerar as desigualdades, a pobreza e a precariedade crescentes, o que faz com que lutar contra as diferenças seja algo tão imperativo. Tudo repousa sobre a ambição de colocar nas mãos das pessoas, dos cidadãos, dos atores, as chaves de seu bem-estar cotidiano. Assim, as prioridades são definidas para responder às necessidades dos grupos sociais, dos habitantes que vivem em situações mais difíceis, que têm menos poder de serem ouvidos e menos ferramentas para se fazerem entender. Para isso, os caminhos que associam parceria e participação são reconhecidamente indispensáveis, mesmo que eles demandem energia e convicção.

Em termos de organização funcional, os dispositivos de promoção de saúde recusam-se a ser programas fechados "de respostas prontas", e se apresentam como um processo que é construído , "um caminho que se faz ao caminhar", por meio da participação, devendo se adaptar aos contextos locais e evoluir com o passar do tempo. Mas, será esta postura um "fazer em conjunto" que deseja avançar, de uma maneira dinâmica, para uma construção conjunta e para a criação de espaços e de debates ${ }^{(3)}$, ou será ela uma "demagogia" que se utiliza do tema modernista da participação, quando, na realidade, todas as decisões já foram tomadas? Esta dubiedade nos remete às autoridades políticas, responsáveis por "definir" as prioridades, no caso da saúde. A ambigüidade se mantém no termo "definir". É autoritária a prioridade definida por meio de um "saber" das necessidades da população ou trata-se de um "engajamento" da autoridade pública em face das demandas dos habitantes locais construído em um espaço de debate e resultado de um trabalho dialógico entre os profissionais da saúde e aqueles que não têm o conhecimento técnico-científico? Entre os especialistas, a idéia de participação parece mais encantadora do que efetiva, isso quando não faz rir aqueles que são responsáveis por colocá-la em prática!

(3) SCHALLER J. J. Construir um viver junto na democracia renovada. Educação e Pesquisa, São Paulo, v. 28, n. 2, 17 p., jul./dez. 2002. 
Este trabalho pretende interrogar, a partir da situação na França, estas "boas intenções e práticas" que são, quase sempre, "piedosas", cobertas de certezas. Pretendemos também esmiuçar certos procedimentos que colocam freios na criatividade coletiva. E, nos arriscaremos a pôr no centro do debate um outro "círculo" de decisão coletiva.

\section{UMA RUPTURA DE SENTIDO}

O interesse de uma abordagem em termos de promoção da saúde é tentar uma ruptura essencial, distanciando-se de uma visão da saúde dos indivíduos, por meio somente do prisma da doença e da tecnicidade médica.

Lembremo-nos desta evidência funcional, a medicina moderna, pela sua especialização, fragmenta o corpo do doente exclusivamente do ponto de vista do órgão defeituoso. Mas, o doente não pode fazer desaparecer esta única parte problemática de seu corpo. Assim, é um reducionismo considerar a razão médica segundo apenas os protocolos técnicos que fazem parte do exercício atual da medicina. Esta abordagem pode ser necessária, mas perde a visão da globalidade do doente. Ela repousa sobre um modo de pensar no qual a saúde e a doença se situam em um continuum bipolar. Esta visão implica que a doença seja vista como uma perda, unicamente como uma perda, e nega, até um certo ponto, o fato de que ela pode ser a ocasião de um recomeço(4). A medicina separou a história subjetiva da doença como uma nova dimensão da vida. Tanto é que inúmeras pessoas dizem o tempo todo aos profissionais de saúde: "existe uma vida psíquica da doença. Falar de uma vida psíquica da doença, é recusar de imediato a autonomia da representação mental em relação à doença, para avançar em uma hipótese segundo a qual a doença é um fato total"(5).

Uma política de promoção da saúde objetiva também se separar de uma política de prevenção, que tem como meta reduzir os fatores de risco de doenças, o que se traduz por ações relativamente exteriores ao meio em questão. A prevenção se mantém impregnada pelo modelo biomédico e epidemiológico e as noções de fatores individuais de riscos. Esta é uma abordagem vertical dos programas de saúde, visando as funções, órgãos, uma população alvo e o objeto de intervenção. O termo promoção da saúde implica, pelo contrário, na participação de todos na análise e na melhoria das práticas de saúde. Ela pretende se estabelecer em um modelo global, a partir de uma abordagem horizontal, articulada com o modo de vida e com a população, sujeito de sua própria vida. Tomando uma formulação de Patrick

(4) LE BLANC, G. La vie psychique de la maladie. Revue Esprit, Paris, n.1, p. 109-122, janv. 2006. (5) Id. Ibid., p. 111. 
Viveret(6), todo ser humano tem, ao menos, uma profissão: ele é chefe de projeto de sua própria vida.

É necessário aprofundar esta tensão entre verticalidade e horizontalidade $^{(7)(8)}$. Continuemos nossa análise do que são, mais freqüentemente, os dispositivos de promoção de saúde entre as injunções participativas destacadas e a realidade do envolvimento recíproco entre os profissionais e os cidadãos.

Nos programas de promoção da saúde, a população local deve ser procurada e deve ter liberdade de expressão. No entanto, esta participação se reduz, normalmente, a uma simples consulta. Os cidadãos são raramente associados às decisões, eles apenas "participam" de um programa concebido pelos "profissionais/especialistas" conhecedores de suas "necessidades". A idéia subjacente desenvolvida em torno da participação, a de "fazer participar em", revela uma concepção passiva de participação. Somente os cidadãos que desejam "fazer parte" participam verdadeiramente e se exprimem. Estamos diante de uma dicotomia entre uma "participação meio" e uma "participação processo".

A "participação meio" é uma técnica utilitarista para se alcançar o sucesso do projeto e a mobilização de recursos. A ideologia própria deste modo de intervenção é a do resultado, da quantidade, da aparência; os resultados devem ser vistos, os profissionais não podem se enganar e o projeto deve ter êxito. Esta "participação meio" pode se reduzir a uma instrumentalização das pessoas, tornando-se um simples dispositivo que facilita a tomada de decisões que, na visão daqueles que decidem, correm o risco de serem recusadas; ou pior, simplesmente uma ferramenta de legitimação. Os decisores consultam, dão à palavra, mas cuidando do que é dito e do que é proposto. Nestes casos, trata-se de fazer falar para melhor fazer calar, no lugar de refletir sobre o que é dito.

A "participação processo" aspira a reforçar o envolvimento dos cidadãos para que eles adquiram e exerçam um potencial crítico. A participação aqui é um processo para criar o debate, a confrontação, e se inscreve sob a perspectiva de uma busca de um mundo em comum $^{(9)}$. É uma participação política sob o título de uma democratização da democracia; ela permite aos

(6) VIVERET, P. Etre le chef de projet de sa propre vie, entretien avec le Secours Catholique, Caritas France. Paris, 2004. Disponível em: <http://www.secours-catholique.asso.fr/entretien_452.htm>. (7) SCHALLER, J.-J. Du vertical à I'horizontal: une ouverture politique stratégique. In: CŌRNIÈRE H.; GUAQUĖRE, D. (Dirs.). Être directeur en action sociale aujourd'hui: Quels enjeux? Paris: L'Harmattan, 2005. p. 151-162.

(8) SCHALLER, J.-J. Entre verticalité et horizontalité: une question pour l'évaluation des politiques sociales. In: BIARNÈS J.; DELORY-MOMBERGER, C. (Dirs.). L'acteur social: le sujet et l'évaluation des politiques sociales. Nantes: Editions Pleins Feux, 2006. p. 37-51.

(9) CALLON, M.; LASCOUMES, P.; BARTHE, Y. Agir dans un monde incertain: essai sur la démocratie technique. Paris: Seuil, 2001. 
cidadãos produzirem palavras próprias. Esta "participação processo" implica na necessidade de centralizar todo o dispositivo de intervenção sobre a pessoa, o que significa, estar centrada sob o sujeito como o coração do sistema de transformação da ação. O objetivo é de promover a democracia: focar na capacidade de cada um de produzir sua vida.

Se uma política de promoção de saúde se fundamenta sobre bases horizontais, construídas sobre uma rede de confiança recíproca, ela mostra aos profissionais da saúde que eles devem dar lugar a seus interlocutores, a fim de que eles se constituam conjuntamente em atores do desenvolvimento local. Este modo de intervenção necessita que os profissionais de saúde se arrisquem, passando de responsáveis pela saúde dos indivíduos para responsáveis pela compreensão das pessoas, dentro de suas complexidades e das complexidades de seus cotidianos.

Significa reconhecer que os cidadãos possuem um saber próprio sobre sua saúde e que eles têm em mãos meios de ação complementares aos procedimentos profissionais. Trabalhar localizadamente a saúde já é agir sobre o conjunto da saúde dos cidadãos: mobilizar as pessoas, favorecer a expressão coletiva e reduzir as distâncias dos aparelhos de intervenção. Todas as pessoas devem se relacionar com o projeto, assim, não há "população alvo" e, conseqüentemente, não há estigmatização. Uma política de promoção da saúde em bases horizontais consegue mobilizar e produzir recursos coletivos; o objetivo é reforçar a capacidade de expressão e de ação das pessoas. Aqui, a promoção da saúde repousa sobre orientações democráticas e se recusa a enquadrar os cidadãos no papel de consumidores de cuidados. Há uma série de questões envolvendo deficientes, doentes, pacientes, usuários, consumidores e cidadãos que mostram uma mudança da relação dependência/autonomia em direção à participação mútua, competências coletivas e a uma perspectiva de modelos globais de saúde. A promoção de saúde compreende tanto a promoção de direitos dos pacientes como a dos direitos dos indivíduos e dos cidadãos, uma cidadania da saúde.

Como destacou J. A. Bury ${ }^{(10)}$, trata-se de política de saúde compreender a palavra dos pacientes, defender seus direitos, Ihes dar acesso à informação e ao poder de decisão dentro do sistema de atenção à saúde.

Como desenvolver a participação, o envolvimento recíproco entre os indivíduos e os grupos, a fim de se construir modalidades coletivas de práticas e de tomada de decisão? Como co-produzir?

(10) BURY, J. A. Education thérapeutique et démocratie sanitaire: du quotidien au politique. Revue Francophone de Psycho-Oncologie, Paris, n. 4, p. 113-119, 2003. 
Estes elementos nos levam à formulação de algumas questões mais amplas, tendo como suporte os trabalhos de J. Donzelot ${ }^{(11)(12)(13)(14)}$ de análise sobre as cidades.

De acordo com este autor, as políticas sociais, na França, visam restaurar o laço social que remete, freqüentemente, a uma preocupação de enquadramento e de moralização vertical. Como reconstituir o capital social que cria uma confiança entre as pessoas; confiança recíproca que se estabelece, de alguma forma, na horizontalidade?

Como passar de uma magistratura social em termos de instituições e de autoridade que se caracteriza por aspectos defensivos e voluntaristas, para uma comunidade cívica que se caracteriza por aspectos ofensivos e pragmáticos?

Como transformar políticas que se apóiam no consentimento e na cidadania (a representação cidadã) em políticas que têm como base a confiança recíproca e a identidade comunitária, nas forças vivas locais?

Como construir objetivos que não sejam somente o de restabelecer a confiança nas instituições - reencontro da legitimidade da autoridade competente -, desenvolver os direitos dos cidadãos e gerar compensações, mas objetivos que também facilitem a transformação, reestabelecendo a autoconfiança, a auto-estima e desenvolvendo o poder local; objetivos que levem as pessoas a se responsabilizarem coletivamente?

Como permitir que as pessoas desenvolvam suas capacidades de intervir e não apenas consultá-las?

Como retomar esta confiança recíproca, ponto central do fazer em conjunto, quando toda a história francesa, se apóia na dupla representação?

\section{UMA DUPLA DELEGAÇÃO - CIENTÍFICA E POLÍTICA}

Atualmente, estamos diante de duas delegações que produzem rupturas graves: a primeira separa os especialistas dos cidadãos leigos; a segunda, distancia os políticos (os eleitos) dos cidadãos comuns.

(11) DONZELOT, J.; MÉVEL C.; WYVEKENS, A. Faire société, la politique de la ville aux Etats-Unis et en France. Seuil, Paris, 2003.

(12) DONZELOT, J. Les nouvelles inégalités et la fragmentation sociale. Revue Esprit, Paris, n.11, nov. 2003.

(13) Id. Quand la ville se défait: quelle politique face à la crise des banlieues, Seuil, Paris 2006.

(14) Id. Démocratie et participation: l'exemple de la rénovation urbaine avec Renaud Epstein dans Forces et faiblesses de la participation, Esprit, Paris, n. 7, juil. 2006. 
Esta dupla delegação é tratada notadamente nos trabalhos de $B$. Latour $^{(15)}$ e de $M$. Callon \& e outros ${ }^{(16)}$, partindo da constatação das dificuldades que as democracias representativas têm em administrar situações de incertezas, as quais podem ser reagrupadas em duas categorias: de um lado, aquelas que dizem respeito ao nosso conhecimento do mundo - o que sabemos nós do mundo?; de outro, aquelas que tratam da composição do coletivo - do que é feito o coletivo no qual vivemos?

O "que sabemos do mundo" produz a primeira delegação que conduz a uma ruptura entre a esfera científica e o mundo dos leigos, pretendendo evitar a confusão de papéis. "A produção da verdade, do acordo, apenas se dá no campo fechado, entre especialistas. São eles que devem decidir a validade dos saberes. Traga os desacordos à praça pública e, rapidamente, a desordem reina. Permita-se aos leigos participarem da discussão de experiências e de seus resultados e, rapidamente, nada mais pode ser medido."(17) Deste primeiro corte, nasce uma base "inabalável" de saberes certos e pacificadores sobre os quais pode se desenvolver o discurso político e que devem conduzir a expressão de um interesse geral.

É aqui que entra em cena a segunda delegação, resultado de uma segunda ruptura. Esta é uma "delegação atribuída pelos cidadãos comuns aos seus eleitos com o propósito de construir o coletivo"(18). Resulta desta democracia representativa um "corpo político constituído de indivíduos (os cidadãos) dotados de vontades e de preferências perfeitamente asseguradas, a democracia representativa exclui toda a incerteza sobre a composição do coletivo, uma vez que este coletivo se encontra reduzido a um agregado de vontades individuais que presume-se sejam perfeitamente conscientes de si mesmas"(19).

Esta situação se inscreve em uma dimensão histórica de mais de 350 anos, quando o Cardeal de Richelieu (1585-1642) teorizou e colocou em prática a idéia de que o interesse do Estado se impõe a todos, o rei aí incluído, e assim construiu os primeiros elementos da noção de interesse geral; noção esta que ainda hoje é central, sob o prisma da luta contra as desigualdades e pela solidariedade! Como destaca $P$. Delmas ${ }^{(20)}$, o dever dos dirigentes é o de fazer prevalecer a razão sobre os afetos e as emoções. Em seu "Testamento Político" Richelieu afirma que "o homem deve soberanamente fazer reinar a razão, o que requer não apenas que ele não faça nada sem ela, mas

(15) LATOUR, B. Ré-assembler le social, introduction à une théorie de l'acteur. Paris: La Découverte, 2006.

(16) CALLON, M.; LASCOUMES, P.; BARTHE, Y., op. cit.

(17) Id. Ibid., p. 169.

(18) Id. Ibid., p. 169.

(19) Id. Ibid., p. 171.

(20) DELMAS, P. II n’y a pas de malheur français. Paris: Grasset, 2007. 
também, que o obrigue a fazer com que todos aqueles que estão sob sua autoridade a reverenciem e a sigam religiosamente"(21).

No mesmo momento, R. Descartes (1596-1650) escreve o "Discurso do Método"(22) onde ele apresenta seu projeto de pesquisa de uma ciência universal. Não é por acaso, que os escritos de Richelieu e de Descartes sejam contemporâneos. Descartes foi para o pensamento racional o que Richelieu foi para a política. O Estado Moderno e o Progresso são assim irmãos gêmeos na França. No século 17, este Estado Moderno assume totalmente a condução da sociedade e a mantém até os dias de hoje.

A legitimidade do Estado se baseia em sua eficácia racional. Para tudo e para todos, ele é o administrador do cotidiano e a garantia do amanhã, como a forma do Estado-providência dos anos gloriosos (trente glorieuses 1945-1975).

A história da construção das políticas sociais francesas pode se resumir a uma tensão permanente entre a instituição fundadora do serviço público e uma lógica de auto-organização da sociedade. A primeira pressiona por uma estatização crescente das atividades sociais, em geral, e da política social, em particular. Já a segunda, se mostra por meio de diversos grupos e, mais particulariamente, pelos movimentos de ação social, expressão da sociedade civil.

Como destaca J.-M. Bélorgey ${ }^{(23)}$, em uma redefinição de Estado-providência, dos Serviços Públicos ou do Interesse Geral, deve-se poder pensar a articulação entre as proteções coletivas indispensáveis e as áreas de responsabilidade da iniciativa individual. Por que as singularidades individuais não podem se estender no centro dos espaços públicos, em uma tensão entre o público - com suas regras e ferramentas de avaliação - e o privado - com sua dimensão "incomensurável"? Diante das novas concepções de políticas sociais, a intervenção social não pode mais ser um trabalho de modelagem. Seu objeto principal é o de ser uma busca exclusiva da liberdade e da autonomia, articulando-se com as normas sociais em transformação.

Isto significa que o poder público, ou seja, o Estado, e seus desmembramentos e administrações, não tem o monopólio sobre o interesse geral. $\mathrm{O}$ interesse geral pode ser tratado fora do poder público e chegamos aqui ao lugar dos movimentos de ação social.

De outro modo, seria o mundo desta dupla delegação, no qual os leigos procuram os especialistas para a produção de certezas "Senhor doutor,

(21) DU PLESSIS, Armand Jean. (Cardinal, Duc de Richelieu). Testament politique. Paris: Editions Complexe, 1990. [1689].

(22) DESCARTES, R. Discours de la méthode. Paris: Gallimard, 1992. [1637].

(23) BÉLORGEY, J.-M. L'usager et ses droits au cœur de la démarche associative. Communication. Paris: Conseil Supérieur du Travail Social, 18 juin, 2001. 
você que sabe e em quem eu tenho confiança, cuide da minha vida" — ou aonde os cidadãos comuns confiam aos seus representantes eleitos o cuidado de estruturar uma coletividade segura e garantida.

\section{A CONFIANÇA: ENTRE ABANDONO E RECIPROCIDADE}

A esta questão de dupla renúncia soma-se uma segunda dificuldade, ela também histórica, que é a da confiança/abandono. A partir de uma reflexão sobre a relação de cuidado, $N$. Zaccaï-Reyners ${ }^{(24)}$ trata de duas figuras clássicas da especulação normativa, querendo produzir as condições de uma relação equilibrada: a da competência/confiança e a do direito.

De acordo com este autor, a primeira figura — da competência /confiança - se articula mais particularmente com a fórmula: a confiança que encontra o conhecimento. O paciente se coloca para o médico, detentor do saber e do poder, a quem ele deve obediência e confirança, numa espécie de abandono ao outro. Lembremo-nos o que escreveu Goffman em "Asiles”, tratando da relação psiquiátrica: "a única condição compatível com suas obrigações frente à instituição e à profissão consiste em escutar as queixas do paciente, persuadindo-o de que as ditas dificuldades com a instituição, a família, a sociedade etc. são, de fato, dificuldades pessoais, e the sugerir como solução, para seus problemas, a reorganização de seu universo interior" (25). Dentro desta figura de competência/confiança, estamos diante da presença de uma ação em direção ao indivíduo, a qual lembremos, no nível dos aparelhos de decisão, trata-se mais de uma abordagem terapêutica. As intervenções são de natureza corretiva, de readaptação, reeducação, ortopédicas. Elas se inscrevem em um quadro de normalização dos indivíduos, marca essencial do vocabulário utilizado.

Neste primeiro cenário, paternalista, o indivíduo experiente - o profissional de saúde - é ao mesmo tempo juiz e parte: "eu sei o que é bom para você, eu que sou um 'conhecedor' face à você, 'leigo, doente, deficiente”.

Pode-se notar que esta primeira figura enxerga a relação sob o prisma da negociação interpessoal, mobilizando os atributos da esfera privada (confiança, esperança, crédito, consciência, devotamento, estima). A relação médico/doente está ancorada em uma concepção referente aos meios de ação, como o da identificação e empatia.

A segunda figura - a do direito - denuncia os pontos obscuros da primeira e reclama sua tradução social e jurídica. Como tudo no mundo do

(24) ZACCAÏ-REYNERS, N. Respect, réciprocité et relations asymétriques: quelques figures de la relation de soin. Revue Esprit, Paris, n. 1, p. 95-122, janv. 2006.

(25) GOFFMAN, E. Asiles. Paris: Les Editions de Minuit, 1968. p. 429. 
trabalho, a relação de cuidado ganharia dignidade sob a pressão organizada de pessoas em situação de doença, que se vêem como grupos sociais suscetíveis de portar reivindicações e de obter proteção jurídica de certos direitos. Vê-se que esta segunda via, em termos de direito, considera essencial a relação sob o prisma da negociação coletiva, mobilizando os atributos da esfera pública. A relação médico/doente associa-se a uma lógica da justiça, remetendo ao mecanismo do conflito de interesses, sendo a luta a forma de ação.

Os limites da figura jurídica destacam que certos elementos determinantes das relações institucionais escapam à inteligência do direito, em particular, tudo o que se refere à vida emocional no centro das interações sociais. É o mesmo que acontece com a figura da confiança, na qual os limites valem igualmente para os recursos da empatia ou da autoprojeção visando chegar ao conhecimento do que é bom para o outro.

O que nos parece merecer destaque é que estas duas formas de abordagem se ligam na vontade de estabelecer artificialmente uma relação equilibrada (ou seja, igualitária, justa, digna, respeitável, razoável, sólida). Aqui, manifesta-se uma apreensão sobre o respeito ao outro que remete à metáfora do equilíbrio das vontades: a limitação dos abusos dos mais poderosos seria resultado da pressão eqüitativamente repartida entre os desejos não congruentes. Surgiria uma espécie de ponto de equilíbrio moralmente sustentável, capaz de garantir a benevolência mútua. Introduzir o respeito em relações assimétricas demandaria, então, intervir sobre a distribuição de atributos de maneira a reduzir o desequilíbrio da relação, no sentido de uma maior proteção à parte considerada minoria ou vulnerável.

Este voluntarismo, ao não querer apenas se referir às categorias socialmente edificadas, como as de direito e de deveres, da igualdade ou da dignidade, não estaria escondendo a questão da não transformação das situações subjacentes, do não agir em face das desigualdades e, no campo da relação de saúde - o que significa dizer cuidados, acompanhamento , de não querer se arriscar diante da irredutibilidade dos desejos em jogo?

Em uma relação de acompanhamento não se pode perder as relações de proximidade e de interdependência, que engajam os parceiros de maneira emocional. Desconhecer estas dimensões de projeção e de emoção poderia muito bem ocultar certas fontes de humilhação ou de desprezo?

E aqui reaparece a questão que embaralha as injunções participativas: atrás da dupla confiança/direito mascara-se, freqüentemente, as relações de humilhação e desprezo. E, mais uma vez, nos encontramos diante da mesma questão: como articular estes atores — os profissionais, os habitantes e as autoridades públicas - para a garantia do interesse geral e da construção conjunta? 
De fato, na França, não dispomos de uma longa tradição de democracia participativa, pois, a ação pública "acredita verdadeiramente apenas em seus agentes e não nos cidadãos e (...) considera que tratar o lugares (ou equipamentos), importa infinitamente mais do que oferecer às pessoas a confiança nelas mesmas"(26). Assim, é necessário proceder a uma verdadeira inversão de perspectiva, a título de um tipo de avaliação dinâmica, onde, ao prestar um serviço, oferecer uma estrutura ou o que quer que seja, se espera uma prestação de contas ao público, que condiciona, por sua vez, o engajamento eficaz de seus agentes funcionais e das pessoas envolvidas: aqui está o ponto central deste modo de intervenção para promoção. Para produzir uma real mudança no regime de ação, é necessário que este aja sobre duas partes: as pessoas e os agentes, e que cada uma destas categorias se sinta impelida pela outra e aprenda a considerá-la. "Se as pessoas não podem julgar um programa, refletir sobre sua constituição, elas não se envolvem com sua realização" (27) O envolvimento e o engajamento recíprocos são a contrapartida de uma avaliação democrática e dinâmica dos procedimentos e formas de ação.

Acreditamos que se deve continuar a questionar esta relação - verticalidade e horizontalidade - entre a necessidade de um sistema que preste contas à população e o envolvimento eficaz desta população no funcionamento deste sistema.

No campo da intervenção social, a necessária capacidade de reação, diante das demandas cada vez mais flutuantes, obriga a não se pensar mais em uma integração vertical de todas as funções, especialidades, de todos os profissionais em uma máquina única. Tem-se aqui um outro posicionamento que pode ser o de uma rede de uma associação, na qual cada entidade traga, em um determinado momento, suas concepções, conhecimentos, qualificações para oferecer os serviços mais adequados aos cidadãos, à cidade, à sociedade civil. Esta horizontalidade produz troca de conhecimentos e de práticas, construindo as "inteligências coletivas", com base na experiência que muda a relação com os especiliastas, com os "conhecedores de nossas necessidades". Devemos tentar uma horizontalidade da decisão e nos arriscar a uma abertura de construção conjunta com os cidadãos, os beneficiários que também ousam interagir uns com os outros! Nos aliarmos.

Isto não quer dizer uma articulação entre saberes formais e saberes da experiência? Não importa que o conjunto de um território - os cidadãos, as associações, os empreendedores - pense em produzir coletivamente projetos nos quais ele possa se engajar? Queremos abordar esta questão, por meio da construção do conceito de "lugar aprendente"(28).

(26) DONZELOT, J. Les nouvelles inégalités et la fragmentation sociale, cit.

(27) DONZELOT, J.; MÉVEL C.; WYVEKENS, A., op. cit.

(28) SCHALLER, J.-J. Un lieu apprenant: de l'habitus à l'historicité de l'action dans. Orientation Scolaire et Professionnelle Insertion, Biographisation, Éducation, Paris, v. 36, n. 1, p. 83-93, mars. 2007. CNAM/INETOP. 


\section{O LUGAR APRENDENTE}

Sob a perspectiva do sujeito ativo que se transforma ele mesmo em transformando o mundo de incertezas no qual vive, gostaríamos de fixar nossa atenção sobre uma questão particular, a do "lugar", espaço ao mesmo tempo físico e mental onde se desenrola o agir social.

Mas, por que lugar e não território? A noção de território é bastante abrangente na França, o que torna sua definição difícil, ambígüa, contraditória, complexa e polissêmica, como mostra de maneira pertinente G. Gontcharoff(29).

Hoje, este termo remete, essencialmente, às práticas políticas, sociais, administrativas e burocráticas; o cruzamento de perspectivas de ação diversas. Não trataremos aqui daquilo que se tornou comum na França, o território das administrações. É o espaço onde se exerce a competência desta ou daquela administração ("este daqui é o meu quintal", quer dizer, de minha competência).

Na França, é quase impossível simplificar ou unir estes territórios, apesar dos repetidos esforços, dos trabalhos em parceira ou em rede. Cada ministério, cada direção conserva os seus: as circunscrições sociais, os recursos de diferentes juridições, as regiões militares, as avaliações das universidades, os boletins escolares, as organizações territoriais hospitalares, de imposto, de correio, a Agência Nacional de Emprego (Agence national pour l'emploi - ANPE), os "bolsões de emprego" e os "bolsões de habitação".

Mesmo que, na década de 1960, esta noção tenha sido um símbolo, a partir da zona rural, da vontade de utilizar a idéia de território como cimento de uma ação cidadã coletiva, nascida na sociedade civil, atualmente, ela nos parece marcar a verticalidade dos modelos de gestão decisionais e controle burocrático ${ }^{(30)}$. O conceito de lugar, em sua acepção de "lugar aprendente", tentará se descolar, para dar sentido a uma horizontalidade da criatividade coletiva.

A noção de lugar remete à relação que o indivíduo aí tem consigo próprio e com os outros: o lugar é homólogo e constitutivo de si e do outro. $E_{\text {Enrikin }}^{(31)}$ afirma que a relação da pessoa com o mundo e da pessoa com os outros é construída por um discurso que joga com elementos subjetivos e obejtivos do lugar e da comunidade. Duas dimensões de lugar se encontram

(29) GONTCHAROFF, G. Territoire. In: BARREYRE, J.-Y.; BOUQUET, B. CHANTREAU, A.; LASSUS, P. (Dirs.). Dictionnaire critique de l'action sociale. Paris: Bayard Editions, 1995. p. 411-413.

(30) DELMAS, P., op. cit.

(31) ENTRIKIN, J. N. "Lieu 2", In LÉVY, J. LUSSAULT, M. (DIRS.) Dictionnaire de la géographie et de l'espace des sociétés, Belin, EspacesTemps.net, II paraît, 19.03.2003. Paris, 2003. Disponível em: <http://espacestemps.net/document411.html>. 
assim em tensão: o lugar nasce de uma geometria que permite saber onde estão ou não os objetos que ele contém (coisas e seres); mas, também, em uma dimensão racional, o lugar depende destes mesmos objetos da mesma maneira que eles necessitam do lugar, dentro de uma perspectiva de vir a ser. Como destaca $A$. Berque (32), o lugar é o espaço de "crescimento-conjunto", dentro da concretude do mundo sensível. Os lugares fazem parte, então, das redes de interesses e de experiências que vivem os sujeitos: os lugares se formam e "aprendem", por sua vez, enquanto se formam e aprendem os sujeitos que lhes habitam. Os indivíduos transformam os lugares e estas transformações afetam o que eles são e o que eles fazem.

Como pode um lugar ser um espaço onde alguém se forma, um "lugar aprendente"? Como o lugar participa da ação coletiva enquanto expressão de identidade cultural e de solidariedade? Isto passa pela rede de saberes que nele circulam e a ele se ligam.

É a pista sugerida por J. Landrieu ${ }^{(33)}$ na sua introdução da noção de território "aprendente", em seu questionamento sobre o conceito de competências coletivas. A autora insiste sobre a importância dos saberes na construção do "eu" e na construção do "nós": "eu existo pelo que eu sei, e porque eu sei”, "nosso saber coletivo constitui a 'verdade' de nosso agir em conjunto".

Um lugar atravessa a rede de ação que ele facilita, atravessa a implementação de redes de atores que o cruzam e "aprendem", porque ele permite traçar o conjunto de relações que são também um conjunto de tradução, notadamente, dos processos de passagem recíproca entre os saberes formais e os saberes da experiência. Cada elo da rede do lugar pode se tornar um evento, uma bifurcação, estar na origem de uma nova circulação de fluídos que traduzem a ação coletiva. A noção de "lugares aprendentes" remete à capacidade de ação coletiva dos atores e ao processo de historização que lhes submetem as práticas, as experiências e as ações de transformação deles próprios. Neste sentido, todo lugar aprende e ensina e esta constatação obriga a uma mudança de perspectiva da parte dos atores responsáveis por intervir junto à população.

Atualmente, a força da ação coletiva repousa sobre a aposta de atribuir a um coletivo pensante o que há de mais íntimo sobre a personalidade humana, a capacidade de reflexão" (34). A transformação produzida por um "coletivo

(32) BERQUE, A. Lieu 1. In: LÉVY, J.; LUSSAULT, M. (Dirs.). op. cit.

(33) LANDRIEU, J. Formes plurielles de l'agir ensemble: les "nous" inventifs. In: HEURGON, E.; LANDRIEU, J. Colloque de Cerisy. Prospective du présent/d'un siècle à l'autre IV, Des "nous" et des "je" qui inventent la cité. La Tour d'Aigues: Edition de l'Aube, 2003. p. 32.

(34) FLECK, L. Genèse et développement d'un fait scientifique. Paris: Les Belles Lettres, 2005. p. 62. [1934]. 
pensante" se apóia sobre o leque de competências que permitem apreciar os campos de força presentes e que constituem a potencialidade da situação. B. Latour ${ }^{(35)}$ segue pela mesma direção uma vez que ele lembra que o essencial hoje não é se fechar em um quadro de referências "imutáveis", mas de poder seguir as associações que permitem aos atores passarem de um lado ao outro. Ele usa a noção de apego para seguir os momentos nos quais os atores encontram um caminho a fim de tornar mais duráveis as interações constantemente flutuantes.

\section{UM OUTRO CÍRCULO DA DECISÃO COLETIVA}

De fato, trata-se de ousar. Mas, para que se possa ousar, no nível decisório, deve-se questionar "quem são os atores? Em benefício de quem eles agem, se associam, se engajam? Em quais lugares? Em quais momentos? Segundo quais procedimentos de trabalho e de trocas"?(36) Trata-se de valorizar um caminho no qual os processos importam tanto quanto os conteúdos e que, atento às iniciativas circunstanciais, estimula uma inventividade coletiva portadora de futuros desejáveis.

As pessoas, desde que sejam reconhecidas como sujeitos produtores de suas próprias existências, não aceitam mais as decisões autoritárias vindas de cima e se afirmam como jogadores e detentores de poder (aquele que recusa) e de um saber (como cliente, usuário, cidadão, habitante). Estamos em uma dinâmica na qual "o reconhecimento precede o conhecimento". De fato, como reforça $P$. Delmas ${ }^{(37)}$, os dirigentes franceses "não ousam mais governar por cima das pessoas e não sabem como governar com as pessoas. O Estado não é mais uma vontade, somente uma administração sem legitimidade política. O procedimento somente subsiste, pois, não é nem dirigente, nem cidadão, com seu teatro de papel possante, que rege o mundo em uma abstração crepuscular".

A troca da decisão pelo procedimento e a regra administrativa estão no centro de uma desconfiança generalizada. Desconfiança dos administradores sobre as pessoas; desconfianças das pessoas sobre os aparelhos do Estado. Este sentimento elimina toda a possibilidade de aproximação entre o poder (político, científico e técnico) e os habitantes. A ação se faz contra ou no lugar destes e não com eles. Como esperar um lugar de confiança com

(35) LATOUR, B., op. cit.

(36) HEURGON, E. Pour une prospective du sujet collectif. L'apport de la prospective du présent. In: HEURGON, E.; LANDRIEU, J., op. cit.

(37) DELMAS, P., op. cit., p. 137. 
esta forma de poder? E como esperar dos habitantes o discernimento sobre assuntos complexos, discernimento este que lhes é recusado em cada detaIhe cotidiano?

Para $R$. Sennett(38), a falta de respeito pelo outro parece desde sempre um dos traços que caracterizam "as elites" em face das "pessoas de baixo": poder se permitir não ter respeito pelo outro é um símbolo da classe dos privilegiados. Deve-se renunciar à política da compaixão e a "mentalidade assistencialista", a fim de criar laços verdadeiros, que não sejam de assistência ou depedência, mas de reprocidade. Trata-se de, por meio da inclinação para o acompanhamento do outro, ater-se em trabalhar a favor de uma "política do respeito", em um mundo cada vez mais desigual, onde a pesquisa das dimensões mútuas de reconhecimento é a única condição para criar laços sociais e restabelecer a confiança recíproca. Richard Sennett conclui esta obra interpelando: "Na sociedade, e mais particuliarmente no Estadoprovidência, o problema é essencialmente de saber como os fortes podem respeitar aqueles que são destinados ao fracasso"(39).

Estamos diante de novas formas de decisão e, mais uma vez, de acordo com M. Callon \& al. ${ }^{(40)}$ temos dois modelos:

- Ou estamos frente a uma decisão tradicional, marcada por uma escolha que se quer rompedora e que deseja produzir um momento úni$\mathrm{co}$, um ato, tomada por um ator legítimo e ratificada pela autoridade científica e política. Temos aí a vontade de voltar à Idade do Ouro, ou o Século das Luzes.

- Ou estamos diante de uma decisão incerta, definida como um encadeamento de encontros que deseja produzir uma atividade reiterativa, alinhavando decisões miúdas, engajando uma rede de atores diversos, de acordo com suas responsabilidades e, enfim, reversível, aberta às novas informações ou formulações. Situamo-nos aí numa ação comedida que traz em seu cerne os processos de associação, inseparáveis da noção de ação coletiva. Todos os movimentos dependem da natureza das relações e da capacidade que reconhecemos de fazer existir, ou não, os sujeitos que lhe estão ligados.

\section{OS LUGARES DE UM MUNDO COMUM}

Gostaríamos de ilustrar esta dinâmica particular da ação coletiva, evocando rapidamente os "fóruns híbridos"(41) que uniram especialistas e não

(38) SENNET, R. Respect: De la dignité de l'homme dans un monde d'inégalité. Paris: Albin Michel, 2003.

(39) Id. Ibid., p. 298.

(40) CALLON, M.; LASCOUMES, P.; BARTHE, Y., op. cit.

(41) Id. Ibid. 
especialistas (médicos e doentes, por exemplo) na busca de uma identidade emergente. Para alguém definir sua identidade, há que se compor e que se interessar. Da mesma forma, para o grupo encontrar sua identidade, ele deve ser capaz de fazer valer a particularidade de sua situação, articulandose a uma série de outros atores e interesses, abrindo-se, neste sentido, ao reconhecimento ativo de outras identidades também improváveis e inesperadas. Este produto do fórum híbrido participa do alargamento do mundo em comum. "Este mundo, entre todos aqueles que poderiam surgir, tem que ser negociado, discutido, aprovado, de maneira a transformar as identidades até Ihes tornarem, pelo menos por um instante, compatíveis umas com as outras. É por isso que este mundo pode ser qualificado de comum."(42) $\mathrm{O}$ "bom resultado" não é aquele fundamentado sobre uma verdade absoluta, que pertence ao especialista e que é ratificada pelo leigo; é uma produção que começa e é formulada dentro de um processo de aprendizagem mútua, de ouvir e de respeitar, que permite o surgimento de "uma verdade" portadora de sentido, feita de saberes coletivos (aqueles "científicos" e aqueles da experiência dos "leigos"), propriedade do "coletivo", que utiliza seus conhecimentos para viver, criar e estabelecer relações com o outro.

Aqui, por meio dos "fóruns híbridos", existem três forças que permeiam os lugares aprendentes.

A primeira, do movimento de associação, oferece aos grupos emergentes um começo de existência e de reconhecimento assim como os primeiros meios de expressão. Nestes grupos, é a tensão entre "profissionais/ especialistas" e "não especialistas e habitantes locais" que produzem um mundo comum.

A segunda força é a da mídia, pois ela fornece infra-estrutura que permite a divulgação das posições e das controvérsias, que contribuem, evidentemente, para o aprofundamento da estrutura. A mídia traz o debate para o centro do espaço público.

E, por fim, a terceira força deve assegurar o bom funcionamento dos processos dialógicos e, ao mesmo tempo, ser um recurso para a organização de estruturas de coordenação responsáveis pela defesa do interesse geral, do bem comum. É a definição dos poderes públicos, garantia da ação coletiva da sociedade.

Eis talvez um modo de favorecer uma prática de ação transformadora que coloca a exploração do mundo comum, a aprendizagem, a experimentação, a deliberação, dentro do respeito à pluralidade. A percepção da pluralidade de identidades, interesses e de modos de ser na criação - por meio da experimentação - "de um espaço comum, não concebido como uniformizante e nivelador, surge no centro do desafio político" ${ }^{(43)}$.

(42) CALLON, M. LASCOUMES, P.; BARTHE, Y. op. cit. p. 201.

(43) CORCUFF, P. Pour une éthique de la fragilité. Paris: Armand Colin, 2002. 
As questões referentes ao sentido e ao valor da existência desabrocham na política, entendendo-se "política" como uma tentativa um tanto desarrazoada de criação de um espaço comum entre seres diferentes. Se as políticas da força nos orientam para um ilusório domínio do curso mundo, por meio de certezas, uma política da fragilidade se abriria à incerteza, ao infinito e à singularidade."(44) Devemos nos deixar inundar pela singularidade do outro: o incomensurável. Como dizia J. Oury ${ }^{(45)}$ sobre as questões de saúde, é necessário que nos interessemos pelo entorno, que estejamos atentos, bem atentos. Como se relacionar com o outro? Para tentar compreender o movimento dos sujeitos, suas emoções, paixões, é preciso olhar para o que Ihes interessa e lhes provocar a arriscar-se em uma ação transformadora. O "lugar aprendente", como inscrição de redes de relacionamento, tal como uma escrita sobre a Terra, deveria permitir o refundamento total da fonte de ação coletiva.

Sejamos realistas, demandemos o impossível.

\section{REFERÊNCIAS BIBLIOGRÁFICAS}

BÉLORGEY, J.-M. L'usager et ses droits au cœur de la démarche associative. Communication. Paris: Conseil Supérieur du Travail Social, 18 juin, 2001.

BERQUE, A. Lieu 1. In: LÉVY, J.; LUSSAULT, M. (Dirs.). Dictionnaire de la géographie et de l'espace des sociétés. Belin, EspacesTemps.net, II paraît, 19.03.2003. Paris, 2003. Disponível em: <http://espacestemps.net/ document411.html>.

BURY, J. A. Education thérapeutique et démocratie sanitaire: du quotidien au politique. Revue Francophone de Psycho-Oncologie, Paris, n. 4, p. 113-119, 2003.

CALLON, M.; LASCOUMES, P.; BARTHE, Y. Agir dans un monde incertain: essai sur la démocratie technique. Paris: Seuil, 2001.

CORCUFF, P. Pour une éthique de la fragilité. Paris: Armand Colin, 2002.

DELMAS, P. II n'y a pas de malheur français. Paris: Grasset, 2007.

DESCARTES, R. Discours de la méthode. Paris: Gallimard, 1992.

DONZELOT, J. Démocratie et participation: l'exemple de la rénovation urbaine avec Renaud Epstein dans Forces et faiblesses de la participation, Esprit, Paris, n. 7, juil. 2006.

\footnotetext{
(44) Id. Ibid.

(45) OURY, J. L'invisible; entretien avec Jean Oury, psychiatre, directeur de la clinique de La Borde, réalisé par Nicolas Philibert, 12 mai 2002, Les Films d'lci. Paris: Editions Montparnasse, 2002.
} 
DONZELOT, J. Les nouvelles inégalités et la fragmentation sociale. Revue Esprit, Paris, n.11, nov. 2003.

Quand la ville se défait: quelle politique face à la crise des banlieues, Seuil, Paris 2006.

; MÉVEL C.; WYVEKENS, A. Faire société, la politique de la ville aux Etats-Unis et en France. Seuil, Paris, 2003.

DU PLESSIS, Armand Jean. (Cardinal, Duc de Richelieu). Testament politique. Paris: Editions Complexe, 1990.

ENTRIKIN, J. N. "Lieu 2". In: LÉVY, J.; LUSSAULT, M. (Dirs.) Dictionnaire de la géographie et de l'espace des sociétés, Belin, EspacesTemps.net, II paraît, 19.03.2003. Paris, 2003. Disponível em: <http://espacestemps.net/ document411.html>.

FLECK, L. Genèse et développement d'un fait scientifique. Paris: Les Belles Lettres, 2005.

GOFFMAN, E. Asiles. Paris: Les Editions de Minuit, 1968.

GONTCHAROFF, G. Territoire. In: BARREYRE, J.-Y.; BOUQUET, B. CHANTREAU, A.; LASSUS, P. (Dirs.). Dictionnaire critique de l'action sociale. Paris: Bayard Editions, 1995. p. 411-413.

HEIDEGGER, M. L'être et le temps. Paris: Gallimard, 1972.

HEURGON, E. Pour une prospective du sujet collectif. L'apport de la prospective du présent. In: HEURGON, E.; LANDRIEU, J. Colloque de Cerisy. Prospective du présent/d'un siècle à l'autre IV, Des "nous" et des "je" qui inventent la cité. La Tour d'Aigues: Edition de l'Aube, 2003.

LANDRIEU, J. Formes plurielles de l'agir ensemble: les "nous" inventifs. In: HEURGON, E.; LANDRIEU, J. Colloque de Cerisy. Prospective du présent/d'un siècle à l'autre IV, Des "nous" et des "je" qui inventent la cité. La Tour d'Aigues: Edition de l'Aube, 2003.

LATOUR, B. Ré-assembler le social, introduction à une théorie de l'acteur. Paris: La Découverte, 2006.

LE BLANC, G. La vie psychique de la maladie. Revue Esprit, Paris, n.1, p. 109-122, janv. 2006.

LEFEBVRE, H. Critique de la vie quotidienne: fondements d'une sociologie de la quotidienneté. Paris: L'Arche, 1980. t. 2.

OURY, J. L'invisible; entretien avec Jean Oury, psychiatre, directeur de la clinique de La Borde, réalisé par Nicolas Philibert, 12 mai 2002, Les Films d'Ici. Paris: Editions Montparnasse, 2002.

SCHALLER J. J. Construir um viver junto na democracia renovada. Educação e Pesquisa, São Paulo, v. 28, n. 2, jul./dez. 2002. 
SCHALLER J. J. Du vertical à l'horizontal: une ouverture politique stratégique. In: CORNIÈRE H.; GUAQUĖRE, D. (Dirs.) Etre directeur en action sociale aujourd'hui: Quels enjeux? Paris: L'Harmattan, 2005. p. 151-162.

Entre verticalité et horizontalité: une question pour l'évaluation des politiques sociales. In: BIARNÈS J.; DELORY-MOMBERGER, C. (Dirs.). L'acteur social: le sujet et l'évaluation des politiques sociales. Nantes: Editions Pleins Feux, 2006. p. 37-51.

. Un lieu apprenant: de l'habitus à l'historicité de l'action dans. Orientation Scolaire et Professionnelle Insertion, Biographisation, Éducation, Paris, v. 36, n. 1, p. 83-93, mars. 2007.

SENNET, R. Respect: De la dignité de l'homme dans un monde d'inégalité. Paris: Albin Michel, 2003.

VIVERET, P. Étre le chef de projet de sa propre vie, entretien avec le Secours Catholique, Caritas France. Paris, 2004. Disponível em: <http://www.secourscatholique.asso.fr/entretien_452.htm>.

ZACCAÏ-REYNERS, N. Respect, réciprocité et relations asymétriques: quelques figures de la relation de soin. Revue Esprit, Paris, n. 1, p. 95-122, janv. 2006.

\title{
VERSÃO ORIGINAL EM FRANCÊS
}

\section{Les Politiques de Promotion de la Santé et la Question des LieuX Apprenants}

\author{
Jean-Jacques Schaller ${ }^{(*)}$
}

\section{RÉSUMÉ}

Que peut-être une politique de promotion de la santé si elle ne se risque pas dans des démarches de participation démocratique au titre des implications réciproques entre les professionnels et les habitants des lieux? Or, aujourd'hui, nous sommes face historiquement à deux délégations produisant deux coupures vives. La première qui sépare les spécialistes et des

(*) Université Paris 13/Nord, Centre de recherches interuniversitaire Expérice, ressources culturelles, éducation - Paris 13/Nord - Paris 8/Saint-Denis. E-mail: <schaller@ univ-paris13.fr>. 